\title{
Kuzey Kıbrıs Türk Cumhuriyeti’nde kullanılan damla sulama sistemlerinde tıkanıklık düzeyi ve performans değerlendirmesi
}

\section{Conflict level and performance evaluation of drip irrigation systems in Turkish Republic of Northern Cyprus}

\author{
Servet TEKİN@, Hale GÜMÜŞSOY KAYNAK@, Gülşah BOZOĞLU® \\ Kahramanmaraş Sütçü İmam Üniversitesi, Ziraat Fakültesi, Biyosistem Mühendisliği Bölümü, 46100, Kahramanmaraş, Türkiye \\ Sorumlu yazar (Corresponding author): S. Tekin, e-posta (e-mail): servettekin@yahoo.com \\ Yazar(lar) e-posta (Authore-mail): muh.halegumussoy@hotmail.com,glshbzgl@gmail.com
}

\section{MAKALE BİLGİSİ}

Alınıș tarihi 30 Kasım 2020

Düzeltilme tarihi 05 Aralık 2020

Kabul tarihi 10 Mayıs 2021

\section{Anahtar Kelimeler:}

Kuzey Kıbrıs Türk Cumhuriyeti

Damla sulama

Tikanıklik

Damlatıcı türdeşliği

İstatistiksel damlatıcı üniformitesi

\section{ÖZ}

Çalışma, damla sulama sistemlerinin performans ve tıkanıklık düzeylerini belirlenmesi amacıyla 2018 yılında Kuzey Kıbrıs Türk Cumhuriyeti (KKTC) ilçeleri olan Güzelyurt, Lefkoşa 3, Girne, İskele ve Gazimağusa bölgelerinde toplam 17 üreticiye ait tarımsal işletmelerde yürütülmüştür. Yapılan çalışma geniş kapsamlı olup ada genelinde damla sulama sistemini kullanan üreticiler örnek alan olarak belirlenmiștir. Çalıșmada bölgeler; Güzelyurt "GY", Lefkoșa "L", Gazimağusa "GM", Girne "G" ve İskele "I’" simgeleri ile gösterilmiş ve üretici ismi $(1,2,3$ ve 4) rakamla ifade edilerek konular oluşturulmuştur. Çalışma bölgesinde ki üreticilere ait damlatıcı yapım farklılık katsayısı değerleri çok düşük ve istenmeyen sınır değerlerinin altında çıkmıştır. Çalışmada damlatıcı türdeşlik değeri en düşük \%60.2 ile GM4 üreticisinde, en yüksek değer $\% 89.1$ ile G1 üreticisinde elde edilirken, en düșük istatistiksel damlatıcı üniformite değeri \%49.5 ile GM1 ve en yüksek \%89.1 ile GY1 üreticindeki damla sisteminden elde edilmiştir. Çalışmada bölgelerindeki üreticiler sulama kaynağı olarak Güzelyurt akiferini kullanmaktadır. Güzelyurt akiferi bölgesine düşen yağıș miktarının düşük olması, yöredeki çiftçilerin aşırı akiferden su çekmesi ve denizden akifere tuz taşınımlarının artması akifer suyunun tuzlanmasına neden olmaktadır. Bölgede damla yönteminde akiferden suyun kalitesinin düșük ve denetim birimindeki arıtma fitrelerinin arıtmada yetersiz olmasından dolayı sistemini performansını etkilediği ve tıkanmalara neden olduğu belirlenmiştir.

\section{ARTICLE INFO}

Received 30 November 2020

Received in revised form 05 December 2020 Accepted 10 May 2021

\section{Keywords:}

Turkish Republic of Northern Cyprus Drip irrigation

Congestion

Emitter uniformity

Statistical emitter uniformity

\begin{abstract}
The study was carried out in 2018 in 17 farms belonging to a total of 17 producers: 4 producers in Güzelyurt, 3 in Nicosia, 3 in Kyrenia, 3 in İskele and 4 in Famagusta. The working regions are determined as the regions where the producers who use drip irrigation system effectively and have problems in the system are concentrated. In the study area, drip irrigation system performance and congestion properties were determined and at the end of the study, clogging levels and uniformity parameters were determined. The study was extensive and the producers using drip irrigation system were identified as the sample area. Regions in the study; Güzelyurt "GY", Nicosia "L", Famagusta "GM", Kyrenia "G" and İskele "I" symbols are shown and the producer name $(1,2,3$ and 4$)$ is indicated by numbers. Coefficient variation of the producers in the study area were very low and below the undesirable limit values. In the study, the emitter uniformity value was obtained from the GM4 producer with the lowest $60.2 \%$ and the highest value was obtained from the G1 producer with $89.1 \%$. The lowest statistical emitter uniformity value was $49.5 \%$, and the highest $89.1 \%$ was obtained from the GY1 producer drop system. In the study, it was determined that the water resources in the regions are low in rainfall, high salt content of the farmers in the region due to excessive water withdrawal from the aquifer, and because of this high salt content, it affects the drip system and causes blockages.
\end{abstract}




\section{Giriş}

Tarım sektörü artık sulama suyunun daha etkin kullanımı için hem dünyada hem de kuraklığı yaşayan/yaşayacak olan alanlarda büyük bir baskı altındadır. Tarımda kullanılan su miktarının düzeyi, toplam su kullanım içindeki payı \%70'in üzerindedir. Azalan su kaynakları ve iklim değişikliğinin olumsuz etkileri göz önüne alındığında, tarımda sulama suyunu etkin kullanan yöntemlerin uygulanması kaçınılmaz olmuştur.

Damla sulama, sulama yöntemleri içerisinde eş dağglımlı su kullanımı, yüksek randıman ( $\geq \% 95$ ), sulama suyu tasarrufu (\%30-70) ve işletme kolaylığı bakımından birçok bitkinin sulanmasında ön plana çıkmaktadır (Çetin ve ark. 2010). Dünyada damla sulama uygulamaları 1960 yılından sonra uygulanmaya başlamış ve özelikle teknolojik gelişmeler ile birlikte 1980'li yıllardan sonra tüm dünya ülkelerinde hızlı bir yayılım göstermeye başlamıştır (Ghinassi 2008). Sulamadan beklenen faydanın sağlanabilmesi için suyun toprağa uygun zamanda ve uygun miktarda uygulanması esastır. Bu koşul ancak doğru sulama yöntemi seçimi ile gerçekleşebilir. Doğru sulama yönteminin seçimi kadar önemli diğer bir konu; seçilen sulama yönteminin doğru projelendirilmesi, doğru uygulanması ve bu yöntemin performansının istenen ölçütlerde olmasıdır. Damla sulama sistemleri laboratuvar koşullarında yüksek performans gösterebilen ancak tarla koşullarında çeşitli değişkenlerin devreye girmesiyle bu performansından kayıp yaşayan sistemlerdir. Bu nedenle damla sulama sisteminin iyileştirilmesi ve yeni sistemlerin planlanması için en iyi yol var olan sistemlerin izlenmesi ve değerlendirilmesidir.

Yıllık su potansiyeli yaklaşı 107 milyon $\mathrm{m}^{3}$ olan KKTC'de bunun 80 milyon $\mathrm{m}^{3}$ 'ü yeralt1, 17 milyon $\mathrm{m}^{3}$ 'ü yerüstü olmak üzere 97 milyon $\mathrm{m}^{3}$ 'ü kullanılabilir durumdadır (Y1ldız ve Çakmak 2014). Doğu Akdeniz'deki bir ada olan Kuzey Kıbrıs Türk Cumhuriyeti (KKTC), tamamen yağışa bağlı olarak yarı kurak bir iklime ve sınırlı su kaynaklarına sahiptir. Su talebindeki artışla birlikte son on yılların sık görülen kuraklıklarının su kaynaklarını önemli ölçüde azalttığı ve KKTC'de ciddi su sıkıntısı sorunları ile karşı karşıya kalındığı görülmektedir İklim değişikliğinin etkileri, su kaynaklarının bütünüyle değerlendirmesi için önemli bir konu olarak görülmektedir (Cleridou ve ark. 2014). Ayrica, adanın yer altı su kaynakları, yüzey sulama yöntemleri büyük bir kısmının bilinçsizce kullanılması, artan sanayinin getirdiği kirliliklerin etkisi ve deniz suyunun mevcut su kaynaklarına karışması; içme, kullanma ve sulama suyunun kalitesini giderek düşürmektedir (Elkiran ve Ergil 2006). Tüm bu olumsuzluklar göz önünde bulundurulduğunda üreticiler için çok büyük avantaj sağlayan damla sulama, sudan tasarruf sağlaması açısından KKTC'de çok tercih edilen sulama yöntemi durumundadır (Günyaktı ve ark. 2008). Fakat, adadaki sulama sularında bulunan tuzlar damla sulama sistem unsurlarından olan damlatıcıların tıkanmasına ve beklenilen ürün artışlarında azalamalara neden olmaktadır.

Çalışma, geniş kapsamlı olup ada genelinde yoğun tarımsal üretimin yapıldığı, sulamaların \%90 düzeyinde damla sulama sisteminin kullanıldığı ve damlatıcı tıkanıklık sorunlarının yoğun yaşandığı Güzelyurt, Girne, Lefkoşa, Gazi Mağusa ve İskele bölgeleri ele alınmıştır. Bu çalışmanın amacı, KKTC'deki tarımsal üretim alanlarında yaygın olarak kullanılan damla sulama sistemlerinin performansını ve tıkanıklık özellikleri belirlemektir.

\section{Materyal ve Yöntem}

Çalışma, 2018 yılında Kuzey Kıbrıs Türk Cumhuriyeti (KKTC) ilçeleri olan Güzelyurt'a 4 üretici, Lefkoşa'da 3, Girne'de 3, İskele'de 3 ve Gazimağusa'da 4 olmak üzere toplam 17 üreticiye ait tarımsal işletmelerde yürütülmüştür. Yapılan çalışma geniş kapsamlı olup ada genelinde damla sulama sistemini kullanan üreticiler örnek alan olarak belirlenmiştir.

Çalışmanın yürütüldüğü tarımsal işletmelerdeki damla sulama sistem filtreleri; Hidrosiklon (HS), kum-çakıl (KÇ), disk (D) ve hidrosiklon+disk (HS+D) filtre tiplerinden olduğu belirlenmiştir. Ana boru ve manifold boru hatlarında polietilen (PE) ve PVC borular kullanılmaktadır. Manifold boru çapları 50$90 \mathrm{~mm}$, ana boru çapları, 75-140 mm ve manifold uzunlukları 50$200 \mathrm{~m}$ ve ana boru uzunluğu 100-200 m arasında değişmektedir. Lateral boru çapı 16 ve $20 \mathrm{~mm}$ kalınlığında uzunluğu ise $80-180$ $\mathrm{m}$ arasında değişmektedir (Çizelge 1).

Proje sahasındaki meyve bahçelerinin ve sebze tarlalarının sulanmasında 2- $4 \mathrm{~L} \mathrm{~h}^{-1}$ damlatıcılar kullanılmakta ve bölgedeki tarımsal işletmelerin tümü sulama suyu kaynağı olarak akiferleri kullanmaktadır. Sulama suyu sinıfı C3S1 (yüksek tuzlu sodyumlu) ile C4S1 (çok yüksek tuzlu az sodyumlu) arasında yer alırken, $\mathrm{pH}$ değerleri 7.2-8.1 arasındadır (Çizelge 1).

Çalışma bölgeleri (Güzelyurt, Lefkoşa, Gazimağusa, İskele ve Girne) özellikle damla sulama sistemini etkin olarak kullanan ve sistemde sorun yaşayan üreticilerin yoğun olduğu bölgeler olarak belirlenmiştir. Çalışma alanında damla sulama sistem performansı ve tıkanıklık özellikleri belirlenmiş ve çalışma sonunda laterallerde meydana gelen tıkanma düzeyleri veya oranları, üniformite (eşsu dağılım) parametreleri belirlenmiştir.

Çalışmada bölgeler; Güzelyurt "GY”, Lefkoşa "L”, Gazimağusa "GM", Girne "G" ve İskele "I" simgeleri ile gösterilmiş ve üretici ismi rakamla ifade edilmiştir. Güzelyurt bölgesinde 4 üretici, Lefkoşa bölgesinde 3 üretici, Gazimağusa bölgesinde 4 üretici, İskele bölgesinde 3 üretici ve Girne bölgesinde 3 üretici çalışmada ele alınmıştır.

Ölçümler, açık ve kapalı alanlardaki arazi koşullarında gerçekleşmiş ve lateral hattı üzerinde bulunan damlatıcıların toplam 48'inden çıkan suyun debileri ölçülerek yapılmıştır. Bu amaçla sırasıyla lateral hatlarında yeralan damlatıcıların altına denk gelecek şekilde plastik kap yerleştirilerek 2 dakikada kaplarda biriken su miktarı ölçülerek belirlenmiş ve sonuçlar L $\mathrm{h}^{-1}$ 'e dönüştürülmüştür. Veriler toplandıktan sonra sistem performasını belirlemek amacıyla ortalama damlatıcı debisi $(\bar{q})$, yapımcı farklılık katsayısı (CV); dağılım türdeşliği (EU) ve istatistiksel damlatıcı üniformitesi (Us) belirlenmiştir. Damlatıcı performanslarının belirlenmesinde kullanılan eşitlikler ve sınıflandırılması (Çizelge 2) ve test yapılan bahçelere ait mevcut durum Çizelge 1'de verilmiştir.

Araştırmada alanında damla sulama sisteminde kullanılan sulama suyu, damla sulama sisteminin başından alınmış ve KKTC Tarım ve Doğal Kaynaklar Bakanlığı Tarım Dairesi Müdürlüğü Güzelyurt Toprak - Su laboratuvarında analiz edilmiştir. Sulama sularının kimi kimyasal ölçütlerinin hesaplanmasinda USSL (1954), tarafindan verilen ilkelerden yararlanılmıştır. Çalışma bölgelerinden elde edilen suların kimyasal özellikleri Çizelge 1'de verilmiştir. 
Çizelge 1. Araştırmanın yürütüldüğü işletmelerin üretim alanı, damla sulama sisteminin durumu ve sulama suyu kalitesi Table 1. Production area, condition of the drip irrigation system and irrigation water quality of the research enterprises

\begin{tabular}{|c|c|c|c|c|c|c|c|c|c|c|c|}
\hline \multirow{2}{*}{$\begin{array}{l}\text { Üretim alanı, damla sulama } \\
\text { sistem ögeleri ve sulama } \\
\text { suyunun kimyasal özellikleri }\end{array}$} & \multicolumn{4}{|c|}{ Güzelyurt } & \multicolumn{3}{|c|}{ Lefkoşe } & \multicolumn{4}{|c|}{ Gazimağusa } \\
\hline & GY1 & GY2 & GY3 & GY4 & L1 & $\mathrm{L} 2$ & L3 & GM4 & GM1 & GM2 & GM2 \\
\hline Alan (da) & 15 & 10 & 17 & 14 & 35 & 12 & 10 & 10 & 14 & 35 & 30 \\
\hline Filtre Tipi & $\mathrm{HS}^{\mathrm{a}}$ & $\mathrm{HS}+\mathrm{D}^{\mathrm{b}}$ & $\mathrm{KÇ}$ & $\mathrm{KÇ}$ & $\mathrm{KÇ}$ & $\mathrm{D}^{\mathrm{d}}$ & $\mathrm{D}$ & $\mathrm{HS}+\mathrm{D}$ & HS & $\mathrm{KÇ}$ & HS \\
\hline Lateral Boru Çapı (mm) & 20 & 16 & 20 & 16 & 16 & 20 & 16 & 16 & 16 & 20 & 20 \\
\hline Lateral Boru Uzunluğu (m) & 140 & 120 & 180 & 180 & 160 & 165 & 120 & 100 & 140 & 170 & 150 \\
\hline Damlatıcı Basıncı (atm) & 2.0 & 1.8 & 1.6 & 2.0 & 1.6 & 1.5 & 1.3 & 1.5 & 2.0 & 2.0 & 1.6 \\
\hline Damlatıcı Aralığ $1(\mathrm{~cm})$ & 50 & 50 & 50 & 50 & 50 & 40 & 25 & 20 & 20 & 50 & 50 \\
\hline Sistem yaşı (yıl) & 3 & 2 & 2 & 3 & 2 & 1 & 1 & 2 & 1 & 2 & 2 \\
\hline Sulama Suyu Sinıfi & $\mathrm{C}_{3} \mathrm{~S}_{1}$ & $\mathrm{C}_{3} \mathrm{~S}_{1}$ & $\mathrm{C}_{4} \mathrm{~S}_{1}$ & $\mathrm{C}_{4} \mathrm{~S}_{1}$ & $\mathrm{C}_{4} \mathrm{~S}_{1}$ & $\mathrm{C}_{4} \mathrm{~S}_{1}$ & $\mathrm{C}_{4} \mathrm{~S}_{1}$ & $\mathrm{C}_{4} \mathrm{~S}_{1}$ & $\mathrm{C}_{4} \mathrm{~S}_{1}$ & $\mathrm{C}_{4} \mathrm{~S}_{1}$ & $\mathrm{C}_{4} \mathrm{~S}_{1}$ \\
\hline $\mathrm{ECw}\left(\mathrm{dS} \mathrm{cm}{ }^{-1}\right)$ & 1248 & 1212 & 1254 & 1260 & 2450 & 2500 & 2660 & 3574 & 3440 & 3005 & 2885 \\
\hline $\mathrm{pH}$ & 8.1 & 8.0 & 7.6 & 7.8 & 7.3 & 7.2 & 7.4 & 7.5 & 7.6 & 7.3 & 7.3 \\
\hline \multirow{2}{*}{$\begin{array}{l}\text { Üretim alanı, damla sulama } \\
\text { sistem ögeleri ve sulama } \\
\text { suyunun kimyasal özellikleri }\end{array}$} & \multicolumn{3}{|c|}{ İskele } & \multicolumn{3}{|c|}{ Girne } & & & & & \\
\hline & İ1 & 12 & İ3 & G1 & G2 & G3 & & & & & \\
\hline Alan (da) & 10 & 35 & 7 & 40 & 70 & 25 & & & & & \\
\hline Filtre Tipi & $\mathrm{KÇ}$ & $\mathrm{KÇ}$ & $\mathrm{KÇ}$ & $\mathrm{D}$ & $\mathrm{D}$ & $\mathrm{D}$ & & & & & \\
\hline Lateral Boru Çapı (mm) & 16 & 16 & 16 & 16 & 16 & 16 & & & & & \\
\hline Lateral Boru Uzunluğu (m) & 80 & 125 & 70 & 180 & 160 & 110 & & & & & \\
\hline Damlatıcı Basınc1 (atm) & 1.5 & 1.5 & 1.8 & 1.2 & 1.5 & 1.5 & & & & & \\
\hline Damlatıcı Aralığı (cm) & 20 & 20 & 30 & 30 & 30 & 20 & & & & & \\
\hline Sistem Yaşı (yıl) & 3 & 3 & 2 & 2 & 2 & 2 & & & & & \\
\hline Sulama Suyu Sinıfi & $\mathrm{C}_{3} \mathrm{~S}_{1}$ & $\mathrm{C}_{3} \mathrm{~S}_{1}$ & $\mathrm{C}_{3} \mathrm{~S}_{1}$ & $\mathrm{C}_{4} \mathrm{~S}_{1}$ & $\mathrm{C}_{4} \mathrm{~S}_{1}$ & $\mathrm{C}_{4} \mathrm{~S}_{1}$ & & & & & \\
\hline $\mathrm{ECw}\left(\mathrm{dS} \mathrm{cm} \mathrm{cm}^{-1}\right)$ & 979 & 1100 & 960 & 1854 & 1900 & 1905 & & & & & \\
\hline $\mathrm{pH}$ & 7.7 & 7.6 & 7.7 & 7.8 & 7.9 & 7.8 & & & & & \\
\hline
\end{tabular}

Çizelge 2. Damlatıcı performanslarının belirlenmesinde kullanılan eşitlikler ve sınıflandırılması

Table 2. Equations and classification used to determine dripper performance

\begin{tabular}{|c|c|c|}
\hline Performans belirleme parametreleri ve kullanılan eşitlik & Sinıflandırma & CV $(\%)$ \\
\hline Yapımcı farklılık katsayısı (CV) (ASAE 2002; Decroix ve Malavel 1985) & Çok iyi & $<5$ \\
\hline \multirow{4}{*}{$C V=\frac{S_{d}}{\bar{q}}$} & İyi & $5-7$ \\
\hline & Orta & $7-11$ \\
\hline & Zayıf & $11-15$ \\
\hline & Kabul Edilemez & $>15$ \\
\hline \multirow{2}{*}{ Dağılım türdeşliği (EU) (James 1988) } & & DU (\%) \\
\hline & Çok iyi & $\geq 94$ \\
\hline \multirow{4}{*}{$E U=\frac{\overline{q_{l q}}}{\bar{q}} \times 100$} & İyi & $81-87$ \\
\hline & Orta & $68-75$ \\
\hline & Zayıf & $56-62$ \\
\hline & Kabul Edilemez & $\leq 50$ \\
\hline \multirow{6}{*}{$\begin{array}{l}\text { İstatistiksel damlatıcı üniformitesi (Us) (ASEA 2002) } \\
U_{S}=\left(1-\frac{S_{q}}{\bar{q}}\right) \times 100\end{array}$} & & Us (\%) \\
\hline & Çok iyi & $>85$ \\
\hline & İyi & $70-85$ \\
\hline & Orta & $60-70$ \\
\hline & Zayıf & $50-60$ \\
\hline & Kabul Edilemez & $<50$ \\
\hline
\end{tabular}

$\overline{C V}$ : yapımcı farklılık katsayısı; $S_{d}$ : standart sapma; $\bar{q}$ : ortalama damlatıcı debisi, $\mathrm{L} \mathrm{h}^{-1} ; E U$ : dağılım türdeşliği, \%; qlq: alt çeyrek ortalama damlatıcı debisi, L h ${ }^{-1}, U s:$ istatistiksel damlatıcı üniformitesi

\section{Bulgular ve Tartışma}

\subsection{Lateral boyunca damlatıcı debi değişimi}

Çalışmanın yürütüldüğü Güzelyurt, Lefkoşa, Gazimağusa, İskele ve Girne bölgelerindeki tarımsal işletmelerde ele alınan laterallerdeki damlatıcı debi değerleri ve debi değişme oranları Çizelge 3, Çizelge 4 ve Şekil 1'de verilmiştir. Çalışma sonunda en düşük ortalama damlatıcı debisi $1.04 \mathrm{~L} \mathrm{~h}^{-1}$ değeri L3 üreticinin kullandığı damla sisteminden elde edilirken, en yüksek ortalama damlatıcı debisi $3.62 \mathrm{~L} \mathrm{~h}^{-1}$ ile GM3 üreticinin damla sisteminden elde edilmiştir. Ayrıca, çalışmada ele alınan 48 damlatıcı sayısı $1 / 3$ oranı dikkate alınarak; 1 . ile 16 . damlatıc1 arası sekmente "baş", 17. ile 32. damlatıc1 arası sekmente "Orta" ve 33. ile 48. damlatıcı arasına "Son" olarak bölümlendirilmiş (Çizelge 3, Çizelge 4 ve Şekil 1) ve her bölüm için damlatıcı değişimleri değerlendirilmiştir. Çalışma sonunda, lateral "Baş" bölgesinde ortalama en düşük debi $1.46 \mathrm{~L} \mathrm{~h}^{-1}$ değeriyle $\mathrm{L} 3$ üreticinin lateralinden, en yüksek ortalama debi değerine $4.44 \mathrm{~L} \mathrm{~h}^{-1}$ ile GY2 üretici lateralinden elde edilmiştir. Lateral "Orta" bölgesinde ortalama en düşük debi değerine $0.95 \mathrm{~L} \mathrm{~h}^{-1}$ ile L3 lateralinden elde edilirken, lateral "Son" bölgesinde GM3 konusunda 3.91 L $\mathrm{h}^{-1}$ olarak belirlenmiştir. Lateral orta ve son bölgelerinde en yüksek debi değerlerine sırasıyla $3.91 \mathrm{~L} \mathrm{~h}^{-1}$ ile GM3 üretici lateralinden, $2.77 \mathrm{~L} \mathrm{~h}^{-1} \mathrm{GY} 3$ üretici lateralinden 
Çizelge 3. Güzelyurt, Lefkoşe ve Gazimağusa bölgelerindeki damla sistemindeki damlatıcı debi değerleri ve debi değişme oranları Table 3. Emitter discharge and discharge change rates in drip systems of Guzelyurt, Nicosia and Kyrenia regions

\begin{tabular}{|c|c|c|c|c|c|c|c|c|c|c|c|}
\hline \multirow{3}{*}{ Damlatıcı no } & \multicolumn{11}{|c|}{ Damlatıcı debisi, $\mathrm{L} \mathrm{h}^{-1}$} \\
\hline & \multicolumn{4}{|c|}{ Güzelyurt } & \multicolumn{3}{|c|}{ Lefkoşa } & \multicolumn{4}{|c|}{ Gazimağusa } \\
\hline & GY1 & GY2 & GY3 & GY4 & L1 & L2 & $\mathbf{L 3}$ & GM1 & GM2 & GM3 & GM4 \\
\hline 1 & 3.00 & 5.16 & 5.25 & 3.60 & 3.60 & 3.66 & 1.65 & 2.97 & 3.60 & 4.41 & 3.15 \\
\hline 2 & 3.45 & 5.04 & 4.86 & 3.60 & 3.60 & 3.75 & 1.68 & 3.00 & 3.06 & 4.44 & 3.00 \\
\hline 3 & 3.30 & 4.92 & 5.25 & 3.75 & 3.84 & 4.05 & 1.80 & 3.45 & 2.70 & 4.44 & 2.85 \\
\hline 4 & 3.15 & 4.71 & 4.65 & 4.35 & 4.35 & 4.35 & 1.86 & 3.75 & 2.64 & 4.41 & 2.70 \\
\hline 5 & 3.06 & 4.68 & 4.65 & 4.50 & 2.46 & 2.76 & 2.16 & 3.78 & 2.58 & 4.50 & 3.36 \\
\hline 6 & 3.03 & 4.65 & 4.35 & 3.15 & 3.00 & 2.85 & 1.38 & 3.90 & 2.34 & 4.41 & 3.18 \\
\hline 7 & 3.03 & 4.38 & 4.44 & 3.30 & 3.15 & 2.94 & 1.47 & 1.92 & 2.25 & 4.35 & 2.67 \\
\hline 8 & 3.00 & 4.35 & 4.44 & 3.30 & 3.15 & 3.06 & 1.53 & 1.95 & 2.16 & 4.32 & 2.64 \\
\hline 9 & 2.61 & 4.35 & 4.50 & 3.33 & 3.45 & 3.15 & 1.65 & 2.16 & 1.95 & 4.32 & 2.16 \\
\hline 10 & 2.88 & 4.23 & 4.14 & 3.33 & 1.80 & 3.33 & 1.05 & 2.58 & 1.74 & 4.29 & 2.16 \\
\hline 11 & 2.85 & 4.65 & 4.14 & 3.57 & 1.80 & 3.45 & 1.08 & 2.70 & 1.56 & 4.23 & 2.13 \\
\hline 12 & 2.76 & 4.44 & 4.05 & 3.06 & 1.83 & 3.60 & 1.08 & 1.32 & 1.53 & 4.53 & 2.10 \\
\hline 13 & 2.73 & 3.78 & 3.90 & 3.06 & 1.86 & 1.80 & 1.14 & 1.35 & 1.38 & 4.17 & 1.95 \\
\hline 14 & 2.70 & 3.75 & 3.75 & 3.06 & 1.86 & 1.83 & 1.17 & 1.35 & 1.38 & 4.14 & 1.86 \\
\hline 15 & 2.70 & 3.45 & 3.87 & 3.06 & 2.25 & 2.25 & 1.20 & 1.44 & 1.35 & 4.08 & 1.68 \\
\hline 16 & 2.64 & 3.36 & 3.84 & 3.09 & 1.74 & 2.25 & 1.26 & 1.44 & 1.35 & 4.08 & 1.65 \\
\hline Baş & 2.95 & 4.44 & 4.42 & 3.47 & 2.80 & 3.12 & 1.46 & 2.51 & 2.15 & 4.34 & 2.51 \\
\hline 17 & 2.64 & 3.24 & 3.75 & 3.15 & 1.74 & 2.28 & 1.02 & 1.50 & 1.32 & 4.05 & 1.53 \\
\hline 18 & 2.61 & 3.15 & 3.60 & 3.15 & 1.74 & 2.25 & 1.05 & 1.53 & 1.32 & 3.90 & 1.50 \\
\hline 19 & 2.61 & 4.20 & 3.90 & 2.82 & 1.77 & 2.25 & 1.05 & 1.29 & 1.26 & 3.90 & 1.41 \\
\hline 20 & 2.61 & 4.08 & 3.60 & 2.85 & 1.77 & 2.23 & 1.26 & 1.29 & 1.26 & 3.87 & 1.38 \\
\hline 21 & 2.61 & 4.05 & 3.75 & 2.85 & 1.77 & 2.24 & 0.90 & 1.32 & 1.23 & 3.87 & 1.35 \\
\hline 22 & 2.10 & 3.84 & 3.57 & 2.85 & 1.80 & 2.24 & 0.90 & 1.65 & 1.23 & 3.84 & 1.35 \\
\hline 23 & 2.58 & 3.15 & 3.45 & 3.00 & 1.80 & 2.24 & 0.96 & 1.80 & 1.29 & 3.75 & 1.35 \\
\hline 24 & 2.58 & 3.15 & 3.54 & 3.00 & 1.80 & 2.22 & 1.02 & 1.20 & 1.29 & 3.99 & 1.29 \\
\hline 25 & 2.58 & 3.15 & 3.48 & 2.70 & 1.80 & 1.98 & 0.84 & 1.20 & 1.20 & 3.99 & 1.47 \\
\hline 26 & 2.58 & 3.09 & 3.54 & 2.73 & 1.80 & 2.10 & 0.84 & 1.23 & 1.20 & 3.96 & 1.44 \\
\hline 27 & 2.58 & 3.06 & 3.45 & 2.73 & 1.68 & 2.10 & 0.90 & 1.26 & 1.20 & 3.96 & 1.44 \\
\hline 28 & 2.58 & 3.06 & 3.45 & 2.73 & 1.68 & 2.21 & 0.90 & 1.26 & 1.17 & 3.90 & 1.26 \\
\hline 29 & 2.58 & 3.00 & 3.30 & 2.79 & 1.71 & 2.22 & 0.90 & 1.26 & 1.14 & 4.05 & 1.26 \\
\hline 30 & 2.55 & 3.84 & 3.15 & 2.82 & 1.71 & 2.22 & 0.81 & 1.26 & 1.14 & 4.02 & 1.23 \\
\hline 31 & 2.55 & 2.97 & 3.15 & 3.00 & 1.71 & 2.22 & 0.84 & 1.26 & 1.14 & 3.69 & 1.20 \\
\hline 32 & 2.52 & 2.85 & 3.15 & 3.00 & 1.71 & 2.34 & 0.75 & 1.29 & 1.08 & 3.66 & 1.20 \\
\hline Orta & 2.56 & 3.37 & 3.51 & 2.90 & 1.75 & 2.21 & 0.95 & 1.36 & 1.22 & 3.91 & 1.37 \\
\hline$\Delta \mathrm{q}_{\mathrm{B}-\mathrm{O}}$ & 0.39 & 1.07 & 0.91 & 0.57 & 1.05 & 0.91 & 0.51 & 1.15 & 0.92 & 0.43 & 1.13 \\
\hline$\%$ & 13.26 & 36.24 & 30.71 & 19.33 & 35.63 & 30.91 & 17.19 & 39.07 & 31.30 & 14.42 & 38.47 \\
\hline 33 & 2.49 & 2.76 & 3.30 & 3.00 & 1.71 & 2.40 & 0.75 & 1.14 & 1.08 & 3.63 & 1.17 \\
\hline 34 & 2.49 & 2.64 & 3.15 & 3.03 & 1.74 & 2.40 & 0.78 & 1.14 & 1.08 & 3.15 & 1.14 \\
\hline 35 & 2.46 & 2.61 & 3.15 & 3.03 & 1.80 & 2.40 & 0.81 & 1.17 & 1.23 & 3.75 & 1.14 \\
\hline 36 & 2.46 & 2.61 & 2.94 & 3.06 & 1.53 & 2.46 & 0.81 & 1.20 & 1.23 & 3.75 & 1.29 \\
\hline 37 & 2.43 & 2.58 & 3.15 & 2.61 & 1.56 & 2.46 & 0.72 & 1.08 & 1.20 & 3.69 & 1.26 \\
\hline 38 & 2.43 & 2.58 & 3.15 & 2.64 & 1.56 & 2.70 & 0.72 & 1.08 & 1.20 & 3.69 & 1.08 \\
\hline 39 & 2.40 & 2.58 & 3.15 & 2.67 & 1.56 & 2.22 & 0.75 & 1.14 & 1.29 & 2.64 & 1.08 \\
\hline 40 & 2.40 & 2.37 & 2.94 & 2.70 & 1.65 & 1.77 & 0.75 & 1.20 & 1.29 & 2.34 & 1.08 \\
\hline 41 & 2.40 & 2.76 & 2.70 & 2.70 & 1.65 & 1.80 & 0.72 & 1.14 & 1.26 & 2.25 & 1.08 \\
\hline 42 & 2.37 & 2.70 & 2.70 & 2.70 & 1.65 & 2.31 & 0.72 & 1.05 & 1.20 & 2.25 & 1.05 \\
\hline 43 & 2.37 & 2.64 & 2.70 & 1.77 & 1.20 & 2.34 & 0.72 & 1.05 & 1.20 & 2.10 & 0.87 \\
\hline 44 & 2.31 & 2.64 & 2.22 & 1.95 & 1.35 & 1.35 & 0.66 & 1.08 & 1.05 & 1.98 & 1.14 \\
\hline 45 & 2.28 & 2.64 & 2.31 & 2.07 & 1.44 & 1.35 & 0.69 & 1.14 & 0.96 & 1.95 & 1.11 \\
\hline 46 & 2.25 & 2.34 & 2.25 & 2.10 & 1.44 & 1.50 & 0.69 & 1.14 & 0.78 & 1.86 & 0.75 \\
\hline 47 & 2.25 & 2.34 & 2.25 & 2.16 & 1.50 & 1.20 & 0.72 & 0.60 & 0.72 & 1.77 & 0.66 \\
\hline 48 & 2.16 & 1.95 & 2.31 & 2.25 & 1.53 & 1.32 & 0.72 & 0.66 & 0.60 & 1.65 & 0.60 \\
\hline Son & 2.37 & 2.55 & 2.77 & 2.53 & 1.55 & 2.00 & 0.73 & 1.06 & 1.09 & 2.65 & 1.03 \\
\hline$\Delta \mathrm{q}_{\mathrm{B}-\mathrm{S}}$ & 0.58 & 1.89 & 1.64 & 0.94 & 1.25 & 1.12 & $\mathbf{0 . 7 3}$ & 1.44 & 1.06 & 1.68 & 1.47 \\
\hline$\%$ & 19.60 & 42.60 & 37.20 & 27.12 & 44.49 & 35.98 & 49.79 & 57.61 & 49.46 & 38.81 & $\mathbf{5 8 . 8 5}$ \\
\hline Genel Ortalama & 2.62 & 3.43 & 3.55 & 2.95 & 2.01 & 2.42 & 1.04 & 1.62 & 1.47 & 3.62 & 1.61 \\
\hline
\end{tabular}


Çizelge 4. İskele ve Girne işletmelerinde ele alınan laterallerdeki damlatıcı debi değerleri ve debi değişme oranları Table 4. Emitter discharge and discharge change rates in drip systems of İskele and Famagusta regions

\begin{tabular}{|c|c|c|c|c|c|c|}
\hline \multirow{3}{*}{ Damlatıcı no } & \multicolumn{6}{|c|}{ Damlatıcı debisi, $\mathbf{L ~ h}^{-1}$} \\
\hline & \multicolumn{3}{|c|}{ İskele } & \multicolumn{3}{|c|}{ Girne } \\
\hline & I1 & $\dot{\mathbf{I} 2}$ & $\dot{\mathbf{I} 3}$ & G1 & G2 & G3 \\
\hline 1 & 3.15 & 4.41 & 2.19 & 3.45 & 2.40 & 3.03 \\
\hline 2 & 3.00 & 4.41 & 2.16 & 3.27 & 3.36 & 3.00 \\
\hline 3 & 2.94 & 4.35 & 2.16 & 3.06 & 3.00 & 2.70 \\
\hline 4 & 2.91 & 4.20 & 2.13 & 3.00 & 2.76 & 3.48 \\
\hline 5 & 3.75 & 4.47 & 2.13 & 2.46 & 2.55 & 3.06 \\
\hline 6 & 3.57 & 4.44 & 2.10 & 2.40 & 2.46 & 2.67 \\
\hline 7 & 3.45 & 4.50 & 2.10 & 2.27 & 2.40 & 2.64 \\
\hline 8 & 3.18 & 3.99 & 2.07 & 2.25 & 2.25 & 2.58 \\
\hline 9 & 3.18 & 3.99 & 2.07 & 2.25 & 2.19 & 2.55 \\
\hline 10 & 3.15 & 3.90 & 2.04 & 2.25 & 2.16 & 2.46 \\
\hline 11 & 2.76 & 3.87 & 2.25 & 2.25 & 2.10 & 2.37 \\
\hline 12 & 2.70 & 3.87 & 2.22 & 2.25 & 2.04 & 2.25 \\
\hline 13 & 2.70 & 4.08 & 2.19 & 2.25 & 2.01 & 2.16 \\
\hline 14 & 2.64 & 4.08 & 2.04 & 2.24 & 1.98 & 2.10 \\
\hline 15 & 2.64 & 4.02 & 2.01 & 2.24 & 1.95 & 2.10 \\
\hline 16 & 2.58 & 3.72 & 1.98 & 2.24 & 1.89 & 1.92 \\
\hline Baş & 3.05 & 4.17 & 2.12 & 2.53 & 2.37 & 2.61 \\
\hline 17 & 2.58 & 3.66 & 1.98 & 2.24 & 1.89 & 1.89 \\
\hline 18 & 2.88 & 3.63 & 1.95 & 2.25 & 1.89 & 1.89 \\
\hline 19 & 2.79 & 3.63 & 1.86 & 2.25 & 1.89 & 1.83 \\
\hline 20 & 2.79 & 3.60 & 1.86 & 2.25 & 1.89 & 1.80 \\
\hline 21 & 2.52 & 3.60 & 1.83 & 2.24 & 1.88 & 1.77 \\
\hline 22 & 2.49 & 3.78 & 1.83 & 2.24 & 1.88 & 1.77 \\
\hline 23 & 2.49 & 3.78 & 1.80 & 2.22 & 1.86 & 1.74 \\
\hline 24 & 2.46 & 3.75 & 1.80 & 2.22 & 1.86 & 1.71 \\
\hline 25 & 2.46 & 3.45 & 1.77 & 2.22 & 1.86 & 2.07 \\
\hline 26 & 2.43 & 3.45 & 1.77 & 2.19 & 1.89 & 2.07 \\
\hline 27 & 2.40 & 3.45 & 1.95 & 2.16 & 1.89 & 2.04 \\
\hline 28 & 2.28 & 3.15 & 1.92 & 2.25 & 1.86 & 1.68 \\
\hline 29 & 2.58 & 3.06 & 1.89 & 2.25 & 1.86 & 1.68 \\
\hline 30 & 2.55 & 3.00 & 1.89 & 2.25 & 1.86 & 1.68 \\
\hline 31 & 2.55 & 3.00 & 1.71 & 2.25 & 1.80 & 1.65 \\
\hline Orta & 2.55 & 3.49 & 1.85 & 2.23 & 1.87 & 1.81 \\
\hline$\Delta q_{1}$ & 0.50 & 0.68 & 0.27 & 0.29 & 0.51 & 0.80 \\
\hline$\%$ & 16.82 & 23.16 & 9.19 & 9.92 & 17.24 & 26.98 \\
\hline 32 & 2.55 & 3.60 & 1.71 & 2.25 & 1.77 & 1.65 \\
\hline 33 & 2.52 & 3.48 & 1.68 & 2.25 & 1.89 & 1.65 \\
\hline 34 & 2.25 & 3.48 & 1.68 & 2.07 & 1.89 & 1.65 \\
\hline 35 & 2.16 & 3.48 & 1.68 & 2.04 & 1.62 & 1.65 \\
\hline 36 & 2.16 & 3.48 & 1.65 & 2.25 & 1.59 & 1.71 \\
\hline 37 & 2.04 & 3.45 & 1.65 & 2.25 & 1.58 & 1.71 \\
\hline 38 & 2.04 & 2.76 & 1.62 & 2.25 & 1.56 & 1.71 \\
\hline 39 & 1.95 & 2.70 & 1.62 & 2.25 & 1.56 & 1.62 \\
\hline 40 & 1.77 & 2.67 & 1.59 & 2.25 & 1.56 & 1.62 \\
\hline 41 & 1.68 & 2.55 & 1.74 & 2.25 & 1.47 & 1.59 \\
\hline 42 & 1.68 & 2.55 & 1.74 & 2.25 & 1.47 & 1.59 \\
\hline 43 & 1.65 & 2.43 & 1.71 & 2.25 & 1.74 & 1.56 \\
\hline 44 & 1.56 & 2.40 & 1.59 & 1.95 & 1.65 & 1.56 \\
\hline 45 & 1.56 & 2.34 & 1.56 & 1.89 & 1.62 & 1.56 \\
\hline 46 & 1.56 & 2.25 & 1.56 & 1.86 & 1.41 & 1.50 \\
\hline 47 & 1.53 & 2.19 & 1.53 & 1.80 & 1.35 & 1.47 \\
\hline 48 & 1.50 & 2.16 & 1.50 & 1.77 & 1.14 & 1.44 \\
\hline Son & 1.85 & 2.76 & 1.63 & 2.10 & 1.57 & 1.60 \\
\hline$\Delta q_{2}$ & 1.20 & 1.40 & 0.49 & 0.42 & 0.81 & 1.01 \\
\hline$\%$ & 39.28 & 33.53 & 23.20 & 16.76 & 33.93 & 38.72 \\
\hline Genel Ortalama & 2.47 & 3.46 & 1.86 & 2.28 & 1.93 & 1.99 \\
\hline
\end{tabular}




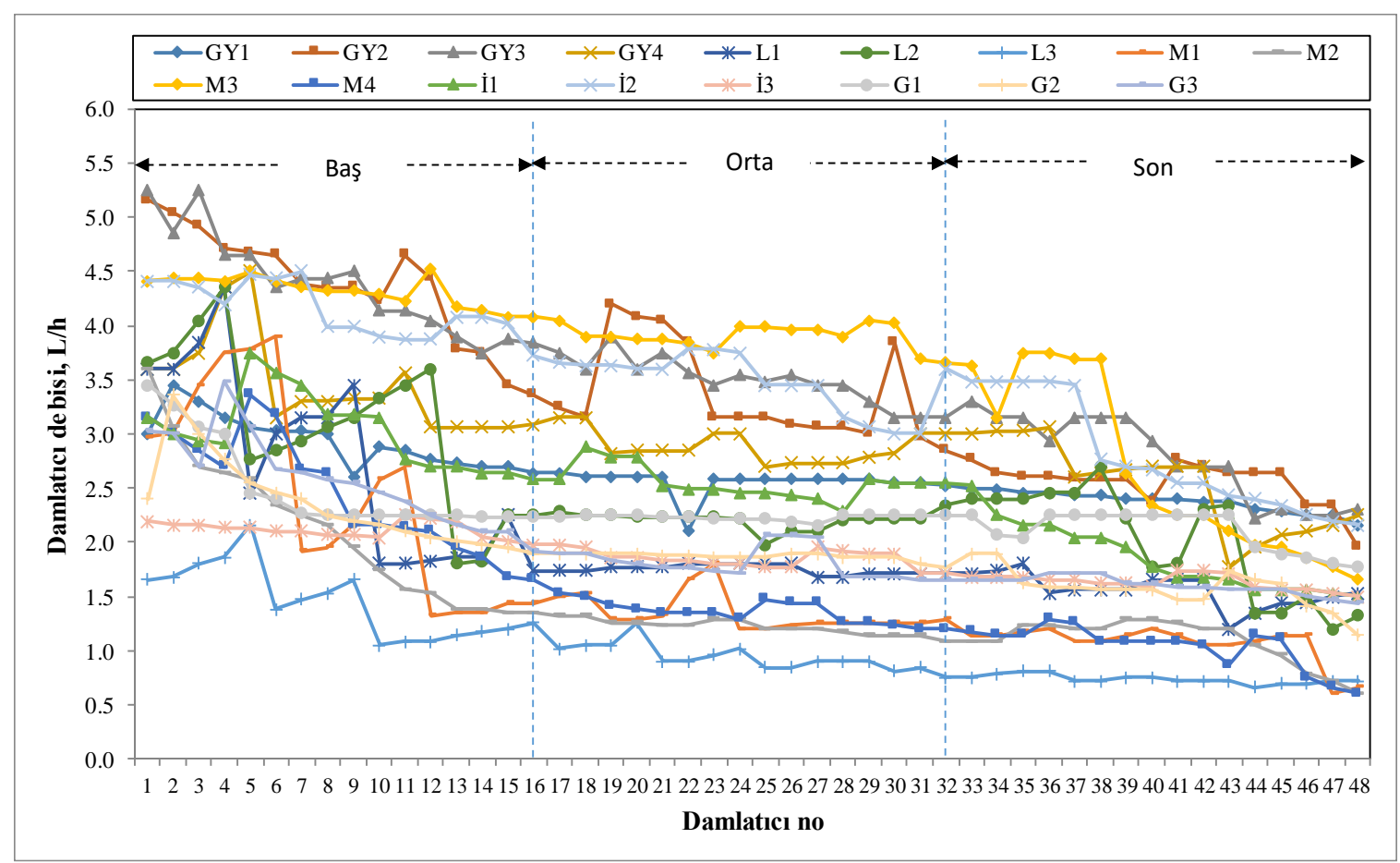

Şekil 1. İşletmelerdeki laterallerde damlatıcı debi değişimi.

Figure 1. Emitter discharge in laterals in enterprises.

elde edilmiștir (Çizelge 3 ve Çizelge 4). Ayrıca, tüm üretici lateral damlatıcılarında değişken dağınık akışlar olduğu saptanmıştır (Şekil 1).

Çalışmada, "baş-orta debi değişim oranı $(\Delta q b-o)$ en düşük $0.27 \mathrm{~L} \mathrm{~h}^{-1}$ İ3 üretici lateralinden, en yüksek $\Delta \mathrm{qb}$-o değerine ise $1.15 \mathrm{~L} \mathrm{~h}^{-1}$ değeri ile GM1 üretici lateralinden elde edilirken, "Orta-Son" debi değişim oranı ( $\Delta$ qo-s) en düşük $0.41 \mathrm{~L} \mathrm{~h}^{-1} \mathrm{G} 1$ üretici lateralinden, en yüksek $\Delta$ qo-s değerine ise $1.89 \mathrm{~L} \mathrm{~h}^{-1}$ değeri ile GY2 üretici lateralinden saptaanmıştır (Çizelge 3 ve 4, Şekil 1).

Çalışmada lateralin "Baş" ve "Son" bölgeleri karşılaştırıldığında lateralin sonlara doğru bütün laterallerde damlatıcı debilerinde azalmalar olduğu belirlenmiştir (Şekil 2). Sistem başıyla sonu arasında debi değişim yüzdesi tüm üretici lateralleri için \%20 ile \%59 değerler arasında olduğu saptanmıştır (Çizelge 3 ve 4). Bu azalmanın sisteme verilen işletme basıncının yetersiz olduğu ve tıkanmaların sisteme etki ettiği söylenebilir. Ayrıca, üreticilerle yapılan görüşmeler sonuçlarıda gösteriyor ki damla sistemini kullanan üreticinin sistem hakkında bilgisinin çok az olduğu ve sistemin projelelenmesinde hatalar olduğu belirlenmiştir.

\subsection{Yapım farklılık katsayısı (CV)}

Her bir damlatıcı belli bir debiye sahip olmasına karşın, işletme basıncı ve yapım farklılık katsayısı tarafından etkilenmektedir. Damlatıcılar imal edilirken basıncın ve isının sabit tutulamaması, kullanılan maddelerin düzgün karışamaması gibi nedenlerden dolayı, damlatıcılarda yapım farklılıkları görülür (Özekici ve Bozkurt 1996). Damlatıcıların sabit debilere sahip olabilmeleri için kullanım ömürleri süresince fiziksel özelliklerini korumaları ve doğa koşullarına dayanıklı olmaları gerekir (Özekici ve Sneed 1995).

Çalıșmanın yürütüldüğü bölgelerdeki üreticilerin damla sistemi test edilmiş, yapım farklılık katsayıları (CV) belirlenmiş ve Decroix ve Malavel (1985) standartlarına göre sınıflandırılmıştır. Çalışma sonunda en düşük yapım farklılık katsayısı 0.11 (orta sinıf) değeriyle GY1 ve İ3 üretici laterallerinden elde edilirken en yüksek CV değerine 0.51 (iyi sınıf) ile GM1 üretici lateralinden elde edilmiştir (Şekil 2). Sonuç olarak çalışma bölgesinde ki üreticilere ait damlatıcı $\mathrm{CV}$ değerleri çok düşük ve istenmeyen sınır değerlerinin altında çıkmıştır. Damlatıcı akış türdeşliğini etkileyen en önemli etkenlerden biriside damlatıcı yapım farklılıklarıdır. Damla sistemlerinde yüksek oranda su dağıtım türdeşliği elde edebilmek için damlatıcıları hatasız yapılması zorunludur. Üretim sırasındaki sıcaklık değişimleri, şekillendirme hataları ve işlenmemiş materyalin tam karışamaması gibi bir çok etken, damlatıcı türdeşliğini etkileyen etmenler olarak sayılabilir (Solomon 1985; Madramootoo ve ark. 1988). Sonuç olarak bütün çalışma bölgesinde CV değerleri istenmeyen değerlerde olduğu çalışmada belirlenmiş ve bölgede kullanılan damla sistemlerinin kalite yönünden düşük olduğu, bölgede faaliyet gösteren firmaların sunduğu damla sistemlerinin daha önce test edilmediği söylenebilir.

\subsection{Damlatıcı türdeşliği (EU) ve istatistiksel damlatıcı üniformitesi (Us)}

Çalışma sonunda damlatıcı debilerinin değişimlerinden dolayı farklı damlatıcı türdeşlik (EU) (Şekil 3) ve istatistiksel damlatıcı üniformitesi değerleri elde edilmiş (Şekil 4). Çalışmada damlatıcı türdeşlik (EU) değeri en düşük \%60.2 ile GM4 üreticisinde, en yüksek değer \%89.1 ile G1 üreticisinde elde edilmiştir. En düşük istatistiksel damlatıcı üniformite (Us) değeri \%49.5 ile GM1 ve en yüksek \%89.1 ile GY1 üreticindeki damla sisteminden elde edilmiştir. Bölgedeki üreticilerin laterallerinden elde edilen EU değerleri sınıflandırıldığında Z (zayıf)-İ-M (iyimükemmel) sınıfları arasında değişirken, istatistiksel damlatıcı üniformite (Us) değeri ortalama olarak 

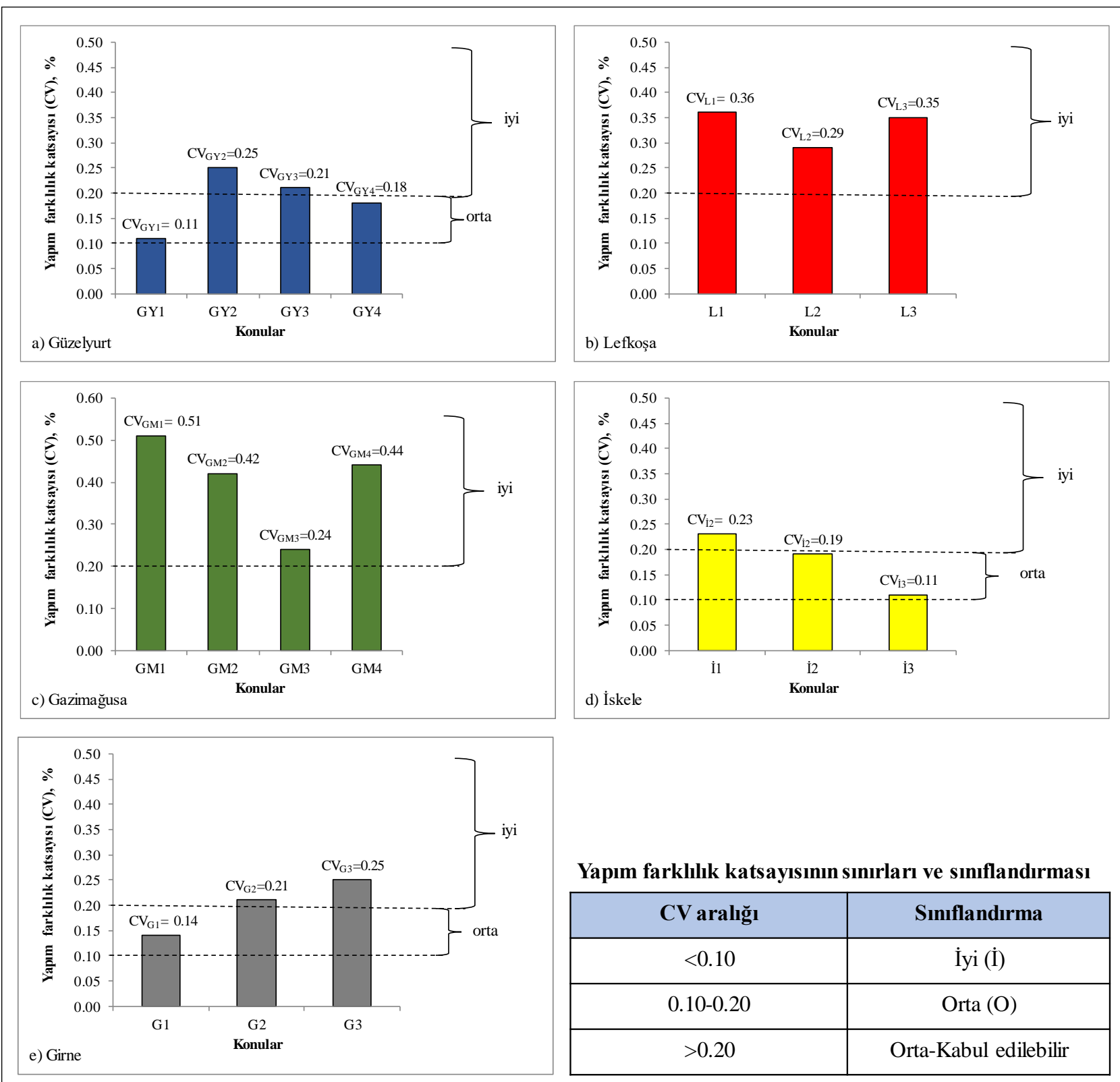

Yapım farklıık katsayısının sınırları ve sinıflandırması

Şekil 2. Damlatıcı yapımcı katsayı değerleri ve sınıflandırması.

Figure 2. Coefficient variation and classification.

\%85.0'den düşük çıktığından uygun değildir (UD) sınıfında çıkmıştır (Şekil 3, Şekil 4).

Damla sulama sistemlerinde sulama randımanı damlatıcılardan çıkan debinin eşdesliğine bağlıdır. Hidrolik değişim ile damlatıcı performansının değişimi temel etmenlerden ikisidir (Özekici ve Bozkurt 1996; Tüzel 1993). Damla sulama sisteminde, lateraldeki sürtünme kayıpları, lateral boyunca basıncın, dolayısıyla damlatıcı debilerinin değişmesine neden olmaktadır. $\mathrm{Bu}$ nedenle hat boyunca eşsu dağılımı sağlanamamaktadır (Demir 1991). Fiziksel, kimyasal veya biyolojik etmenlerden oluşan damlatıcı tıkanıklığı gerekli önlemler alınmadığı zaman, su uygulama türdeşliği ve akış miktarı bakım-onarım masrafları, bitki verim ve kalitesine olumsuz etkiler (Nakayama ve ark. 1979; Çamoğlu 2004). Sonuç olarak, çalışma bölgelerinde yetersiz yağış ve üreticiler yeraltı su kaynaklarını aşırı şekilde tüketmek akifer ve yeraltı suyunun zamanla derinliğinin artmasına neden olmuş ve bölgenin kıyıya yakın olması yer altı su kaynaklarının deniz suyuyla karışmasına ve tuzlanmalarına neden olmaktadır. Sulama suyu kalitesindeki bu düşüş damla sulama sistemindeki damlatıcılarda tıkanıklıklar meydana getirmiştir. Böylece sistem performansında düşüş yaşanmıştır. 

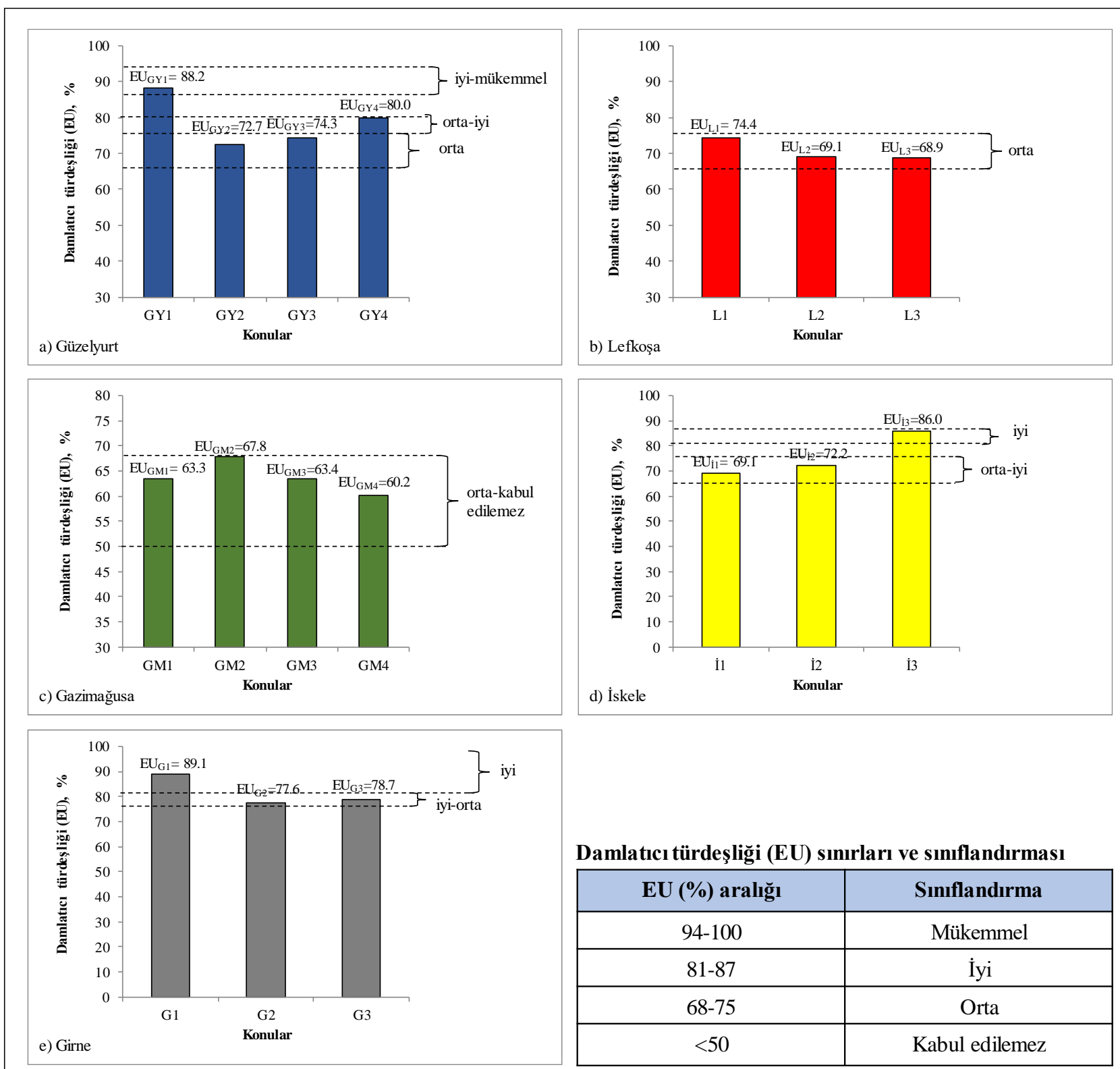

Damlatıcı türdeşliği (EU) sınırları ve sınıflandırması

Şekil 3. Damlatıcı türdeşliği (EU) değerleri ve sınıflandırması.

Figure 3. Emitter uniformity (EU) and classification.

\section{Sonuçlar ve Öneriler}

Çalışma, damla sulama sistemlerinin performans ve tıkanıklık düzeylerini belirlenmesi amaciyla KKTC'de damla sulama yönteminin en yoğun olduğu işletmelerde yürütülmüştür.

Bir damla sulama sistemi planlanmadan önce kullanılacak su kaynağının debisi ve su kalitesi bilinmesi gerekir. Su kalitesinin uygun olmadığı durumlarda, damlatıcılarda meydana gelecek tıkanmaları önlemek veya asgari düzeye indirmek için bazı önlemler alınmalıdır. Çalışmada damla sistemlerinde yaşanan tıkanıklığı bölgesindeki üreticilerin suyun tuz kalitesini farklı yöntemlerle (yağmur suyunu veya Türkiye'den gelen nitelikli suyu karıştırarak) düşürerek su kalitesini arttırarak, kimyasallarla (amino asit, fosforik asit, kireç çözücü), veya damla laterallerini tek yıllık olarak kullanmak yollarıyla giderme çabasındadır. Yöre çiftçisine damla sisteminin etkin kullanması için konuyla ilgili gerekli eğitimlerin verilmesi önerilmektedir.

Bölgede ölçülen basınç değerleri 1.0 atm den daha yüksek veya bilinçsizce sisteme uygulanmaktadır. Bu damla sistemine uygulanan yüksek ve bilinçsizce basınç uygulamaları KKTC gibi enerjinin dışa bağımlı yani pahalı ülkelerde sulama maliyetini büyük oranda artıracağından bilinmeli ve çiftçilere sistem için uygun işletme basıncında çalıştırılmaları önerilmelidir. 

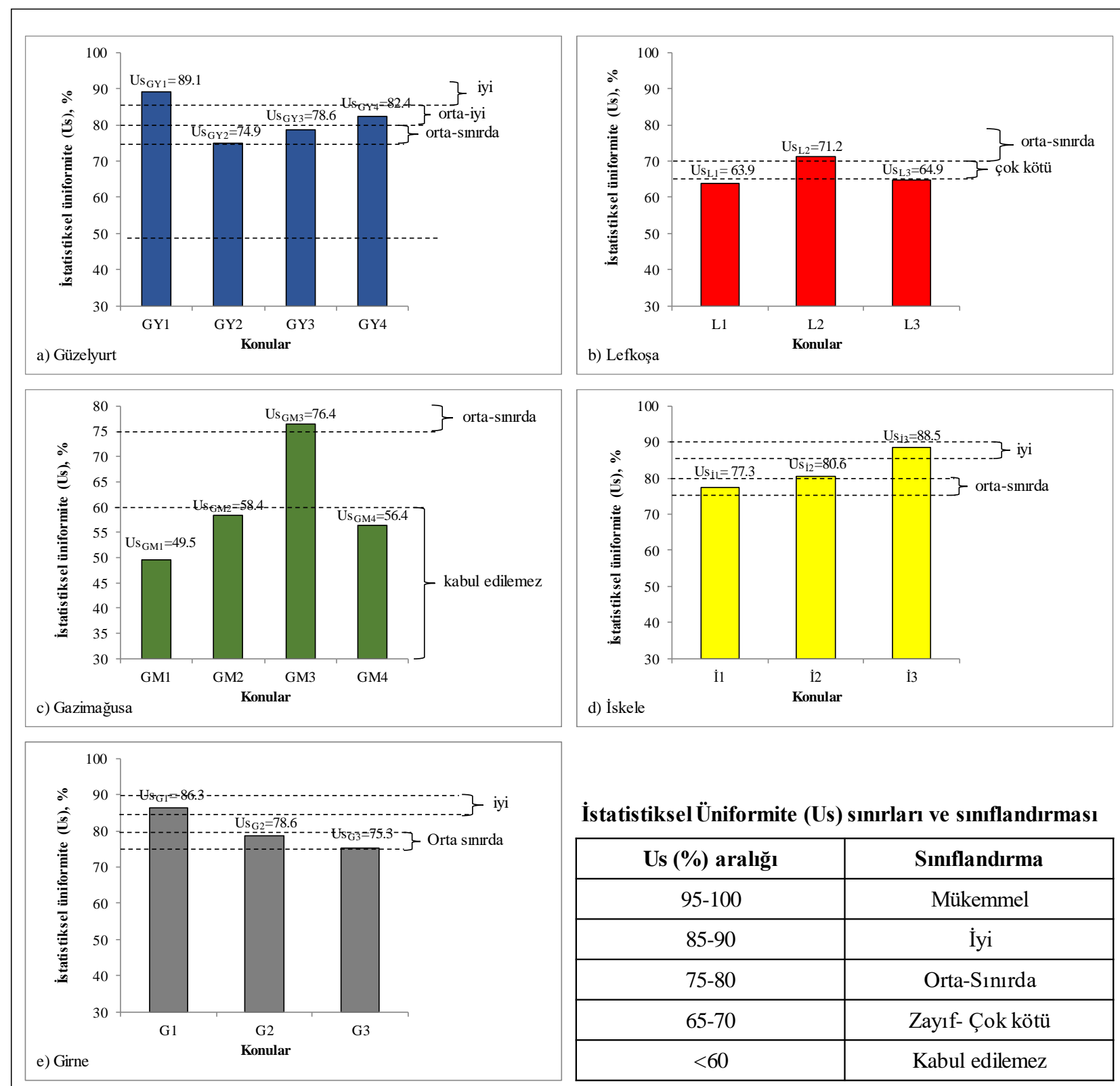

İstatistiksel Üniformite (Us) sımırlan ve sınıflandırması

Şekil 4. İstatistiksel damlatıcı üniformite (Us) değerleri ve sınıflandırması. Figure 4. Statistical emitter uniformity (Us) and classification.

Çalışma bölgesindeki üreticilere ait damla laterallerinin damlatıcı yapım farklılık katsayısı değerleri çok düşük ve istenmeyen sınır değerlerinin altında çıkmıştır. Damlatıcı akış türdeşliğini etkileyen en önemli etkenlerden biriside damlatıcı yapım farklılıklarıdır. Damla sistemlerinde yüksek oranda su dağıtım türdeşliği elde edebilmek için damlatıcıları hatasız yapılması zorunludur. Damla sulama boruları üretici firmaların ürettikleri boruları piyasaya sürerken söz konusu boruya ait bazı özelikleri bir çizelge şeklinde vermeleri firmaların güvenilirliği açısından çok önemlidir. Bu çizelgede boru çapı, damlatıcı aralığı, işletme basıncı, damlatıcı debisi, basınç dayanımı yanında ayrıca söz konusu borunun belirli lateral uzunlukları için yeknesaklık katsayısı ve su dağılım sınıfı ve damlatıcı imalat katsayısı da bulunması uygulayıcılar açısından büyük kolaylık sağlayacağından firmalardan bunları yapmaları tavsiye edilebilir.
Çiftçilerin katalog bilgileri bulunmayan damlama borularını almamaları önerilebilir.

Genelde yörede kullanılan damlatıcıların dağılım üniformitelere çok düşük değerlerdedir. Dağılımdaki bu düşük değerler özellikle bitki gelişimini etkilemekte ve verimde azalmalara neden olmaktadır. Dağılım üniformitesi daha önceden kurulmuş sulama sistemlerinin değerlendirilmesinde daha yaygın olarak kullanılan bir ölçüttür. Dağılım üniformitesinin artırılması için sistemin bakım ve onarım işlemlerinin sağlıklı olarak yapılması tavsiye edilir. Buradan, yüksek dağılım yeknesaklığının ancak iyi bir şekilde bakımı yapılan ve doğru olarak işletilen sistemlerden elde edileceği söylenebilir. 


\section{Teşekkür}

$\mathrm{Bu}$ araştırmada olanaklardan faydalanmamızı sağlayan KKTC Lefkoşa Su Dairesi Müdürlüğüne ve K.K.T.C Tarım ve Doğal Kaynaklar Bakanlığı Tarım Dairesi Müdürlüğü Güzelyurt Toprak - Su Labaratuvar birimine desteklerinden dolayı teşekkürü borç biliriz.

\section{Kaynaklar}

ASAE (2002) Design and Installation of Microirrigation Systems. ASAE EP405.1 Dec. 01, pp. 903-907.

Cleridou N, Benas C, Matsoukas C, Croke B, Vardavas I (2014) Water resources of Cyprus under changing climatic conditions: Modelling approach, validation and limitations. Environmental Modelling \& Software 60: 202-218.

Çamoğlu G (2004) Farklı yapımcı ve yapım özelliklerine sahip damlatıcılarda eş su dağılımının incelenmesi. Yüksek Lisans Tezi, Çanakkale 18 Mart Üniversitesi Fen Bilimleri Enstitüsü, Çanakkale.

Çetin Ö, Eylen M, Sönmez FK (2010) Basınçlı sulama sistemlerinin su kaynaklarının etkin kullanımındaki rolü ve bu sistemlerin yaygınlaşmasında mali desteklerin etkisi. Tarım Bilimleri Araştırma Dergisi 3(2): 53-57.

Decroix M, Malaval A (1985) Laboratory evaluation of trickle irrigation equipment for field system design. In: Third International Drip/Trickle Irrigation Congress. California, USA, pp. 325-338.

Demir V (1991) Türkiye'de Kullanımı Yaygın Olan Damla Sulama Boruları ve Damlatıcılarının İşletme Karakteristikleri Üzerinde Bir Araştırma. Tarımsal Mekanizasyon 13. Ulusal Kongresi, Konya.

Elkiran G, Ergil M (2006) The assessment of a water budget of North Cyprus. Building and Environment 41: 1671-1677.
Ghinassi G (2008) Manual for performance evaluation of sprinkler and drip irrigation systems in different agro-climatic regions of the world. ISBN: 81-89610-11-2 ICID, New Delhi.

Günyaktı A, Ergil M, Çelik B (2008) KKTC Su Sorunları ve Su kaynaklarının Geliştirilmesi. Doğu Akdeniz Üniversitesi Gazimağusa 273-292.

James LG (1988) Principles of Farm Irrigation System Design. John Willey and Sons Inc., New York, pp. 543.

Madramootoo CA, Khatri KC, Rigby M (1988) Hydraulic performances of five different trickle irrigation emitters. Canadian Agricultural Engineering 30: 1-4.

Nakayama FS, Bucks DA, Clemmens AJ (1979) Assessing trickle emitter application uniformity. Transactions of the American Society of Agricultural Engineers 22(4): 816-821.

Özekici B, Sneed RE (1995) Manufacturing variation for various trickle irrigation on-line emitter. Applied Engineering in Agriculture 11(2): 235-240.

Özekici B, Bozkurt S (1996) Determination of hydraulic performances of in-line emitters. Journal of Agriculture and Forestry 23(1): 19-24.

Solomon KH (1985) Global uniformity of trickle irrigation systems. Transactions of ASAE 28 (4) 1151-1158.

Tüzel İH (1993) Damla sulama sistemlerinde sulama yeknesaklığının değerlendirilmesi. Ege Üniversitesi Ziraat Fakültesi Dergisi 30: 119126.

USSL (1954) Diagnosis and Improwement of Saline and Alkali Soils. USDA, Agriculture Handbook no.60, USA, pp. 160.

Yıldız D, Çakmak C (2014) Ülkelerarası Su Transferi Türkiye'den Kıbrıs'a Barış Nehri. Hidropolitik Akademi, Rapor No: 6. 